\title{
Recruitment forecast models for walleye pollock Theragra chalcogramma fine-tuned from juvenile survey data, predator abundance and environmental phase shifts
}

\author{
Tianyang Zhang ${ }^{1}$, Kevin M. Bailey ${ }^{2}$, Kung-sik Chan ${ }^{1, *}$ \\ ${ }^{1}$ Department of Statistics and Actuarial Science, University of Iowa, 263 Schaeffer Hall, Iowa City, Iowa 52242, USA \\ ${ }^{2}$ Alaska Fisheries Science Center, National Marine Fisheries Service, NOAA, 7600 Sand Point Way NE, Seattle, \\ Washington 98115, USA
}

\begin{abstract}
Forecasting recruitment of marine fishes from environmental effects acting upon larvae has proven difficult due to multiple, nonlinear, interacting factors influencing larval survival. We used another approach, which circumvents the period of high egg and larval mortality, and instead improves forecasts from juvenile abundance indices. We compared several statistical recruitment forecast models and demonstrate that an increasing abundance of predators on juvenile walleye pollock Theragra chalcogramma, particularly the arrowtooth flounder Atheresthes stomias, which now dominates the groundfish biomass in the Gulf of Alaska, and autocorrelation caused by intercohort interactions strongly affect pollock recruitment during the juvenile phase. Furthermore, the weight of predictor variables changes with threshold criteria, which are linked to phase shifts in the marine environment. Our results indicate that forecasting recruitment of marine fishes can be improved by considering factors that influence survival after the juvenile period, but also needs to account for changes in community structure and phase shifts in the environment, as opposed to only environmental correlates. Inclusion of these factors is consonant with biological knowledge of the species.
\end{abstract}

KEY WORDS: Population dynamics - Fisheries - Environment - Ocean research - Regime shift · Ecological community $\cdot$ Fish recruitment $\cdot$ Forecast

\section{INTRODUCTION}

Marine scientists have searched for ways to forecast the abundance of commercial fish stocks since the early 1900s (Hjort 1914, p. 227, NOAA 2008), especially for stocks where harvests rely heavily on recruitment of young fish due to depletion of older age groups. However, forecasting recruitment from environmental conditions (Walters \& Collie 1988) or from abundances of early life stages (Mukhina et al. 2003) has proven difficult due to the complexity of multiple interacting factors (Bailey et al. 2005, Houde 2008). Forecasting the abundance of walleye pollock Theragra chalcogramma in the Gulf of Alaska (GOA) would be especially useful because the fishery is largely dependent on the recruitment of strong year classes and has recently been near collapse, having declined to about $22 \%$ of its estimated unfished biomass in 2003 (Dorn et al. 2009).

Walleye pollock is an important component of North Pacific ecosystems, both as a predator and competitor of other fishes, and as prey to seabirds and marine mammals, and it is currently the world's second largest fishery. Walleye pollock abundance in the GOA increased dramatically in the late 1970s with a series of strong year classes and began a long downward trend in the late 1980s; both periods coincided with changes in ocean conditions. However, community structure in the GOA has also changed (Anderson \& Piatt 1999, Litzow \& Ciannelli 2007), and an important source of predation mortality of juvenile pollock, the arrowtooth flounder Atheresthes stomias, has dramatically in- 
creased in abundance over the past 2 decades. In fact, in the 1990s arrowtooth flounder surpassed walleye pollock as the dominant groundfish species (by biomass) in the GOA.

Numerous attempts have been made to forecast walleye pollock recruitment from environmental effects on eggs and larvae (e.g. Lee et al. 2009). In this study we examine juvenile pollock because, generally speaking, recruitment prediction from the abundance of older stages should be more accurate than that from egg or larval abundances (Bradford 1992, Helle et al. 2000) or environmental factors alone (Axenrot \& Hansson 2003). Here we use statistical models to link juvenile survey data to predictor variables that influence their later survival to forecast the recruitment of walleye pollock to the fishery. By testing and comparing several statistical models we examine whether (1) an increasing abun-

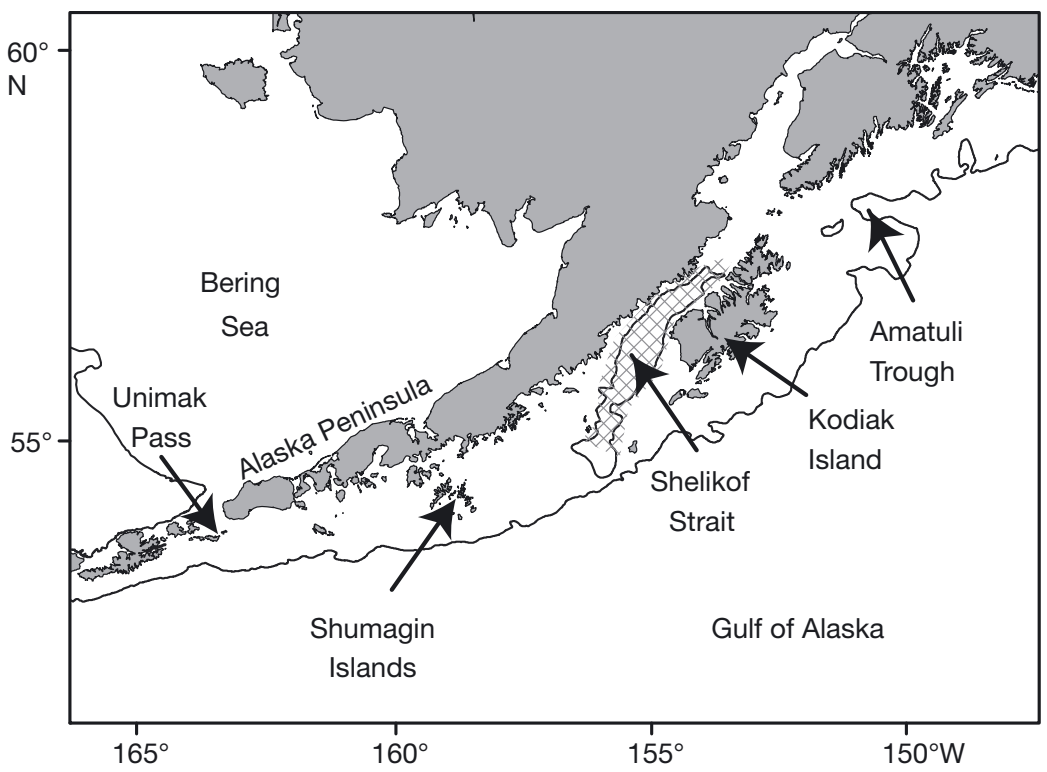

Fig. 1. Theragra chalcogramma. Gulf of Alaska showing key geographical features. The hatched region in Shelikof Strait depicts typical age-1 walleye pollock survey area

dance of predators, specifically arrowtooth flounder, in the GOA strongly affects pollock recruitment, (2) the weight of predictor variables shift with phase (or regime) shifts in the marine environment and (3) intercohort interactions are important. The results presented here indicate that forecasting recruitment of marine fishes needs to account for changes in community structure, rather than just environmental correlates with egg and larval survival.

\section{METHODS}

Walleye pollock spawn in Shelikof Strait, Gulf of Alaska (Fig. 1) from late March to early May. Echo integration-trawl (EIT) surveys have been conducted annually by the Alaska Fisheries Science Center since 1981 (except 1982 and 1999) to assess the biomass of pollock before spawning in the Shelikof Strait area. In early surveys (1981-1991) biomass estimates were obtained with a Biosonics acoustic system and from 1992 onward data were obtained with a Simrad EK echosounder. An index of age-1 pollock juveniles was estimated as the abundance of 9 to $16 \mathrm{~cm}$ fish in the Shelikof Strait EIT surveys (McKelvey 1996) and was reported in Dorn et al. (2009). The abundance of age-4 recruits was taken from Dorn et al. (2006, 2009), estimated from age-structured population models of catch-at-age data in the fishery. Walleye pollock are caught as adults beginning at 4 to 5 years of age. The number of age- 4 recruits is from the western GOA; we assume that the number of age-1 juveniles in the She- likof region is a relative index of juvenile abundance in the western GOA, and that variability in their survival reflects larger-scale patterns. In the early years of the pollock fishery most of the spawning in the GOA occurred in the Shelikof Strait, but over the years, other spawning areas have varied in their contribution. The biomass of age-3+ arrowtooth flounder was taken from Turnock \& Wilderbuer (2007).

The models proposed in this paper are used to study the recruitment of young adult walleye pollock of age 4 from early juvenile fish of age 1, incorporating the effects of predators and environmental factors. Additionally, since the age- 4 recruits are autocorrelated, we depict this autocorrelation using one of the following 2 model structures:

and

$$
y_{4, t+3}=f_{1}\left(y_{1, t}, a_{t}, e_{t}\right)+\xi_{t+3}
$$

$$
y_{4, t+3}=f_{1}\left(y_{1, t}, a_{t}, e_{t}\right)+\sum_{j=m_{1}}^{m_{2}} g_{j}\left(y_{4, t+j}\right)+\varepsilon_{t+3}
$$

where $t$ denotes year, $m_{1}$ and $m_{2}$ are 2 integers (for example, $m_{1}=1$ and $\left.m_{2}=2\right), y_{k, t}$ represents the log abundance of the $k$-yr old pollock in Year $t,\left\{\xi_{t}\right\}$ are colored noise with zero mean and finite variance, i.e. autocorrelated, whereas $\left\{\varepsilon_{t}\right\}$ are independent and identically distributed noises with zero mean and finite variance. Thus, $y_{1, t}$ denotes the log age-1 abundance index in Year $t$ and $y_{4, t+3}$ is the log abundance of age-4 pollock $3 \mathrm{yr}$ after $t_{\text {; }}$ hence, $y_{1, t}$ and $y_{4, t+3}$ equal the density of the cohort of the pollock spawned in Year $t-1$, when they are 1 and $4 \mathrm{yr}$ old, respectively. Additionally, $a_{t}$ denotes the log abundance of arrowtooth flounder, which is the main preda- 
tor of the juvenile pollock in the western GOA, and $e_{t}$ represents a vector of environmental factors in year $t$, which includes the spring sea surface temperature (SST, i.e. the average SST from April to June), the fall SST (the average SST from July to September), the spring sea surface wind speed, the fall wind speed and the mean annual wind speed. The SST variables were derived from average monthly SST interpolated across a longitude band in the GOA from $155.6^{\circ} \mathrm{W}$ to $157.5^{\circ} \mathrm{W}$ and centered at latitude $56.2^{\circ} \mathrm{N}$ (data source: A. Macklin, Pacific Marine Environmental Laboratory pers. comm., www. cdc.noaa.gov/cdc/reanalysis/). The wind speed covariates were computed from sea level pressure data collected twice per day in Shelikof Strait $\left(56^{\circ} \mathrm{N}, 156^{\circ} \mathrm{W}\right)$ (data source: A. Macklin \& M. Spillane, Pacific Marine Environmental Laboratory pers. comm.). The term $f_{1}\left(y_{1, t}, a_{t}, e_{t}\right)$ summarizes the main effects on the recruitment of age-4 pollock. We tried several systems of notation and the preceding format was easiest to follow. A notation system formed around pollock year classes was complicated because of the 2 time sequences for pollock and arrowtooth flounder, and it was difficult to use pollock year class to indicate the time subscript of the flounder. In the model comparison and selection, we employed Akaike's information criterion (AIC) for model comparison and selection. We also used model diagnostic checks such as the residuals' normality test, constant variance and autocorrelation checks among the residuals (ACF and Ljung-Box tests) (see Chapter 8 in Cryer \& Chan 2008) and outlier detection methods.

For Model (1), any autocorrelation in the age-4 recruits beyond that induced by the main regression effects $f_{1}\left(y_{1, t}, a_{t}, e_{t}\right)$ is modeled by the autocorrelated error, $\left\{\xi_{t+3}\right\}$, which, in practice, is specified as some autoregressive (AR) error process. On the other hand, Model (2) uses the lagged recruitment $\left(y_{4, t+j,} j=2,1,0\right)$ to account for any such autocorrelation in the recruitment data. Below, we refer to the autocorrelation in the recruitment beyond that induced by the main effects $f_{1}\left(y_{1, t}, a_{t}, e_{t}\right)$ as the extra autocorrelation. Because the response variable, $y_{4, t+3}$, is the recruitment of age- 4 pollock in Year $t+3$, its lag-1, i.e. the recruitment of age- 4 in the previous year, equals $y_{4, t+2}$. Similarly, $y_{4, t+j}$ in the term $g_{j}\left(y_{4, t+j}\right)$ is the lag- $(3-j)$ recruitment.

The autocorrelation patterns in the recruitment models may result from intercohort interactions in the walleye pollock population. Specifically, we demonstrate 3 such mechanisms in the simple case of linear and noise-free dynamics. One mechanism results in the AR error process as specified in Model (1), and the other 2 mechanisms introduce different lagged recruitment into Model (2).

First, the autocorrelation structure in Model (1) can be justified by cannibalism and/or competition from adult pollock, specified as the age-4+ (age 4 and older) group, in which case the (linear) recruitment dynamics is driven by the following system of equations:

$$
\begin{gathered}
y_{4, t+3}=\beta_{0}+\beta_{1} a_{t}+\beta_{2} y_{1, t}+\omega y_{4+, t} \\
y_{4+, t+1}=\gamma_{4} y_{3, t}+\delta y_{4+, t} \\
y_{3, t+1}=\gamma_{3} y_{2, t}+\tau_{3} y_{4+, t}
\end{gathered}
$$

Eq. (3a) models the recruitment from age-1 pollock to age 4 ; the term $\beta_{1} a_{t}$ models the effects of the arrowtooth flounder on the recruitment and $\omega y_{4+,}$ represent the effects of cannibalism of the age-4+ group on the juvenile pollock and/or competition effects from the older pollock in the recruitment process. It is expected that $\omega$ is negative. (We generally use greek letters to denote unknown model parameters to be estimated from the data.) Eq. (3b) accounts for the survival of the age-4+ group from the previous year given by $\delta y_{4+, t}$ and new members from the age-3 group represented by $y_{4} y_{3, t}$. Eq. (3c) accounts for the survival of age-2 fish to age 3 given by $y_{3} y_{2, t}$ and competition from age- $4+$ pollock modeled by $\tau_{3} y_{4+, t}$. Note that the $\gamma^{\prime}$ s are expected to be between 0 and 1 , and so is $\delta$. Eq. (3a) is a special case of Eq. (1) where $f_{1}$ is a linear function and the error term $\xi_{t+3}$ equals $\omega y_{4+, t}$, which we now show to be an autoregressive process; hence, the error term in Eq. (1) is autocorrelated. Indeed, Eqs. (3b) \& (3c) imply that:

$$
y_{4+, t+1}=\delta y_{4+, t}+\gamma_{4} \tau_{3} y_{4+, t-1}+\gamma_{4} \gamma_{3} y_{2, t-1}
$$

Since the $\gamma^{\prime}$ s are expected to be between 0 and 1 , the coefficient $\gamma_{4} \gamma_{3}$ is probably negligible; therefore, the preceding equation can be approximated by:

$$
y_{4+, t+1}=\delta y_{4+, t}+\gamma_{4} \tau_{3} y_{4+, t-1}
$$

In practice, the preceding relationship holds only on the average, so that a stochastic error term has to be added to the right side of the equation; hence, $\left\{y_{4+, t}\right\}$ is approximately an $\mathrm{AR}(2)$ process, with $\delta$ being the $\mathrm{AR}(1)$ coefficient and $\gamma_{4} \tau_{3}$ being the $\mathrm{AR}(2)$ coefficient. In particular, $\delta$ can be interpreted as the survival rate of the age-4+ pollock. The interpretation of the AR(2) coefficient estimate is more complex as it equals the product $\gamma_{4} \tau_{3}$, which is expected to be negative because of the assumed positivity of $\gamma_{4}$ and the negativity of $\tau_{3}$. As for Model (2), the extra autocorrelation is assumed to be captured by the lagged recruits. Such an autocorrelation structure can be attributed to interactions between the young adult pollock (age 4) and the juvenile pollock, in which case the walleye pollock population dynamics follow the following system of equations:

$$
\begin{gathered}
y_{4, t+3}=\beta_{0,4}+\beta_{2,4} y_{3, t+2}+\tau_{4, t+2}^{*} y_{4, t} \\
y_{3, t+2}=\beta_{0,3}+\beta_{1,3} a_{t+1}+\beta_{2,3} y_{2, t+1}+\tau_{3} y_{4, t+1} \\
y_{2, t+1}=\beta_{0,2}+\beta_{1,2} a_{t}+\beta_{2,2} y_{1, t}+\tau_{2} y_{4, t} \\
a_{t+1}=\varphi a_{t}+\vartheta y_{1, t}
\end{gathered}
$$


Eq. (4a) shows the recruiting process of age- 4 walleye pollock from age 3 , which includes the survival of age-3 fish given by $\beta_{2,4} Y_{3, t+2}$ and the interactions between the age- 4 pollock and the age- 3 fish in year $t+2$ in terms of $\tau_{4, Y_{4, t+2}}^{*}$. The coefficient $\tau_{4}^{*}$ reflects the intergroup interactions in 2 aspects: (1) it measures the competition and/or cannibalism between age-4 and age-3 pollock, and (2) it accounts for misclassification between the age- 4 group and its neighboring age groups, which commonly occurs when a certain portion of a strong year class are incorrectly aged and overflow into adjacent year classes. The competition and/or cannibalistic effects tend to reduce the recruitment of age- 4 pollock, and misclassification probably results in a positive association between the age- 4 recruitment and its lag-1. Since these 2 interactions are opposite in direction, the sign of $\tau_{4}^{*}$ is undetermined in Eq. (4a), which is also the reason for adding an asterisk to this coefficient. Eq. (4b) accounts for the survival of age- 3 pollock from the previous year's age- 2 fish in the term $\beta_{2,3} y_{2, t+1}$, the predation from arrowtooth flounder represented by $\beta_{1,3} a_{t+1}$ and the competition and/or cannibalism between the age- 4 and age- 2 pollock denoted by $\tau_{3} y_{4, t+1}$. In Eq. ( $\left.4 \mathrm{~b}\right), \tau_{3}$ is expected to be $<0$, because it mainly assesses the intergroup competition and/or cannibalism. Similarly, the coefficient $\tau_{2}$ in Eq. (4c) is expected to be negative. Eq. (4d) indicates that the abundance of the flounder predators is related to their last year's abundance and the corresponding age1 pollock abundance, as arrowtooth flounder mainly eats age- 0 and age-1 pollock, as well as some age-2 fish. The coefficients $\varphi$ and $v$ are expected to be positive. Substituting Eqs. (4b-d) into Eq. (4a) yields:

$y_{4, t+3}=\left[\beta_{0,4}+\beta_{2,4} \beta_{0,3}+\beta_{2,4} \beta_{2,3} \beta_{0,2}\right]+\left[\beta_{2,4} \beta_{1,3} \varphi+\beta_{2,4} \beta_{2,3} \beta_{1,2}\right] a_{t}$

$+\left[\beta_{2,4} \beta_{1,3} \vartheta+\beta_{2,4} \beta_{2,3} \beta_{2,2}\right] y_{1, t}+\left[\tau_{4 y_{4, t+2}^{*}}^{*} \beta_{2,4} \tau_{3} y_{4, t+1}+\beta_{2,4} \beta_{2,3} \tau_{2} y_{4, t}\right]$

$=\beta_{0}+\beta_{1} a_{t}+\beta_{2} y_{1, t}+\left[\tau_{4}^{*} y_{4, t+2}+\beta_{2,4} \tau_{3} y_{4, t+1}+\beta_{2,4} \beta_{2,3} \tau_{2} y_{4, t}\right]$

The model represented by Eq. (4e) contains the lag-1 to lag-3 of the recruitment that generates the extra autocorrelation in the recruits of age- 4 walleye pollock. The parameters $\beta_{2, j}, j=2,3,4$ are survival rates that are likely to fall between 0 and 1. If we further assume weak competition and/or cannibalism between the age- 4 and the age- 1 pollock (small $\tau_{2}$ in magnitude), the coefficient of $y_{4, t}$ in Eq. (4e) is negligible compared with the coefficients of $y_{4, t+2}$ and $y_{4, t+1}$. Therefore, the recruitment equation can be simplified as:

$$
y_{4, t+3}=\beta_{0}+\beta_{1} a_{t}+\beta_{2} y_{1, t}+\left[\tau_{4}^{*} y_{4, t+2}+\beta_{2,4} \tau_{3} y_{4, t+1}\right]
$$

The terms within the square brackets of Eq. (4f) measures the lagged recruitment effects on the recruitment of age- 4 pollock. Since the sign of the parameter $\tau_{4}^{*}$ is unclear, we cannot determine the sign of the lag-1 recruitment effect. However, we expect a negative lag2 effect in the recruiting model with the negative $\tau_{3}$ and positive $\beta_{2,4}$. We can further generalize Eq. (4f) by replacing the linear lagged recruitment by nonlinear lag-1 and lag-2 effects in terms of $g_{j}\left(y_{4, t+j}\right), j=1,2$. Similarly, we constructed a mechanistic model that results in explaining the extra autocorrelation in terms of the lag-2 and lag-3 recruitment effects. However, as that model is discredited by the data (see 'Results'), for simplicity we do not elaborate on the third model.

Although we mainly assume linear effects in the above derivation, the models may be rendered more flexible by allowing nonlinear effects in terms of some unknown smooth functions and by including stochastic errors in the models. Indeed, these models then fall into the general framework of the generalized additive mixed models (GAMMs) (Lin \& Zhang 1999, Wood 2006). The recruitment models in the form of Eqs. (1) \& (2) can be represented as a GAMM. For the simple case of single covariate and Gaussian errors, the GAMM takes the following form:

$$
w_{t}=s\left(u_{t}\right)+\xi_{t}, t=1,2, \ldots n
$$

where the response $w_{t}$ bears a nonlinear relationship with the covariate $u_{t}$ and the noise terms $\left\{\xi_{t}\right\}$ are autocorrelated. For the simple case that $\left\{\xi_{t}\right\}$ has a multivariate normal distribution with zero mean vector and covariance matrix $\Lambda$, the log-likelihood of model (5) is given by $-0.5 \times \log |\Lambda|-\{W-\mathrm{s}(U)\}^{\prime} \Lambda^{-1}-\{W-s(U)\} / 2$, up to some additive constant, where $W$ is the vector of response values, $\mathrm{s}(U)$ the vector of the smooth function $s$ evaluated at the covariate values, $|\Lambda|$ is the determinant of the covariance matrix $\Lambda$. For estimating the unknown smooth function, we use the penalized likelihood approach, which tries to find the function estimate that provides good fit to the data and yet assures that the function is not too rough. The penalty term is a multiple of the integrated squared second derivative of the smooth function, i.e. $\lambda\left\{\{\ddot{s}(u)\}^{2} d u\right.$ where the non-negative parameter $\lambda$ is known as the smoothing parameter that describes the trade-off between goodness of fit and smoothness of the function estimate, and $\ddot{s}$ denotes the second derivate of $s$. Altogether, the GAMM can be estimated by maximizing the penalized log-likelihood: $-0.5 \times \log |\Lambda|-\{W-\mathrm{s}(U)\}^{\prime} \Lambda^{-1}-\{W-s(U)\} / 2-\lambda \int\{\ddot{s}(u)\}^{2} d u$.

It should be noted that if the noise terms are uncorrelated over time, then the GAMM becomes the generalized additive model (GAM); see Wood (2006) for details and other estimation methods.

Since a threshold structure was introduced for fitting the main effects in $f_{1}\left(y_{1, t}, \mathrm{a}_{t}, \mathrm{e}_{t}\right)$, we needed to develop a test for the validity of the proposed threshold structure. Considering a possible shift of the arrowtooth flounder spatial distribution from the late 1980s to early 1990s and the occurrence of an environmental regime shift 
about the same time (see below), we further proposed different arrowtooth flounder predation effects before and after a threshold year during that period. A threshold year effect in the models was assessed by testing the null hypothesis $\left(H_{0}\right)$ that the arrowtooth flounder predation effect was present for all years versus the alternative hypothesis $\left(H_{a}\right)$ that it started to become important to walleye pollock survival after a threshold year. A likelihood ratio test was employed to justify the threshold structure in arrowtooth flounder predation. Let $\theta$ be the parameter vector, including the threshold year, $\log L\left(\hat{\theta}_{0, n}\right)$ be the $\log$-likelihood function evaluated at the maximum likelihood estimators under the null hypothesis, and $\log L\left(\hat{\theta}_{n}\right)$ be the maximum log-likelihood function under the general hypotheses. The loglikelihood ratio, $l r$, can be written as $l r=\log L\left(\hat{\theta}_{n}\right)-$ $\log L\left(\hat{\theta}_{0, n}\right)$, which is used as the test statistic. For Model (1) with stochastic error process, the empirical distribution of the test statistic under the null hypothesis is obtained by the following bootstrap approach. Based on the residual vector $(\xi)$ and the correlation matrix $(\Lambda)$ estimated under the null hypothesis, we calculate the normalized residuals, $\hat{\varepsilon}=\hat{\Lambda}^{-1 / 2} \hat{\xi}_{0}$. For each $k=1, \ldots K$, we randomly permute the elements in $\hat{\varepsilon}_{0}$ to get $\hat{\varepsilon}_{0}^{(k)}$. Using the parameter estimator $\hat{\theta}_{0, n}$ and the residuals $\hat{\xi}_{0}{ }^{(k)}=\hat{\Lambda}^{-1 / 2} \hat{\varepsilon}_{0}{ }^{(k)}$, we generate the new recruitment level data $\hat{y}_{4, t+3}^{(k)}=f_{1, \hat{\theta}_{0, n}}\left(y_{1, t}, a_{t}, e_{t}\right)+\hat{\xi}_{(t+3), 0}^{(k)}$. Based on the generated data, $\hat{y}_{4, t+3}{ }^{(k)}$, we calculate $l r^{(k)}$. The empirical distribution of the test statistic is formed from the $l r^{(k)}$ values. Additionally, to form such an empirical distribution based on Model (2), whose error terms are independent and identically distributed, we can generate the new data by bootstrapping the residuals directly. Finally, the p-value of the likelihood ratio test is calculated as the proportion of $l r^{(k)}$ values that are higher than the observed $l r$.

\section{RESULTS}

There was generally a positive relationship between the age- 1 abundance index and the recruitment of walleye pollock to the fishery 3 yr later (Fig. 2). However, the relationship appeared to have shifted downward after 1991, suggesting the presence of emerging factors on age-1 pollock survival. At around the same time, arrowtooth flounder abundance was increasing and surpassed pollock to become the dominant groundfish species in the GOA (Fig. 3). We therefore selected these factors (age-1 pollock abundance, arrowtooth flounder abundance, a threshold effect) and some environmental factors (e.g. temperature) to test and compare in the statistical recruitment prediction models.

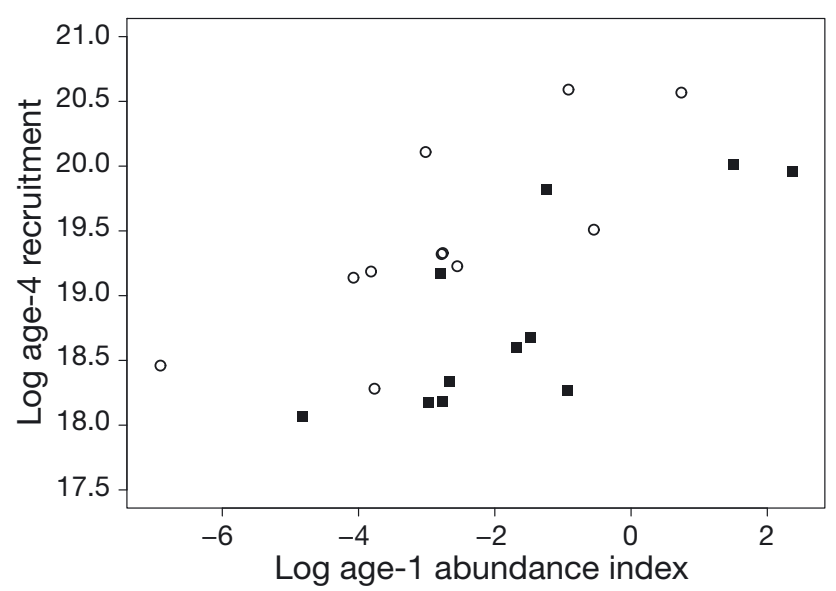

Fig. 2. Theragra chalcogramma. Scatter plot of (log) cohortspecific age-1 walleye pollock abundance versus (log) age-4 recruitment. (O) observations before 1992; (ם) observations since 1992

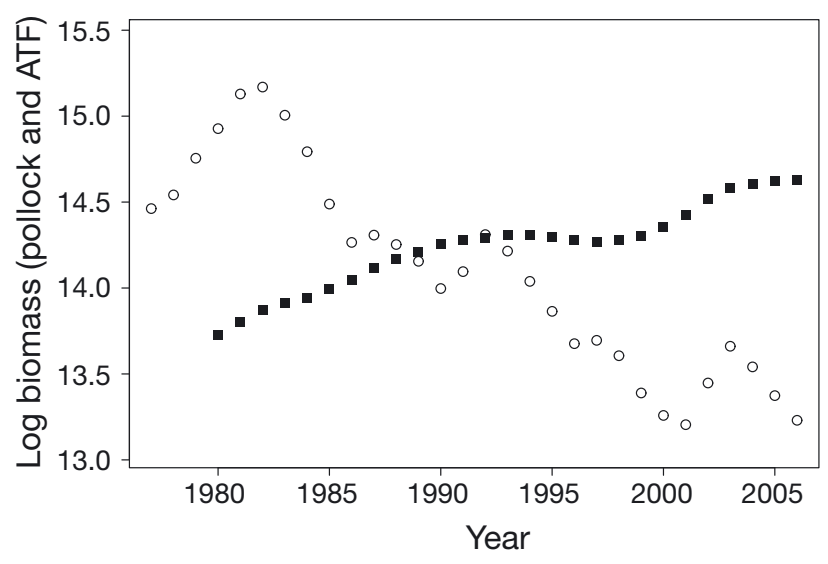

Fig. 3. Theragra chalcogramma. Time plot of (log) walleye pollock biomass and (log) arrowtooth flounder biomass. (O) (log) biomass of age $3+$ pollock; ( $($ ) $(\log )$ flounder biomass

In the 'Methods', we discussed 3 mechanisms to derive the autocorrelation structures in recruitment models. For each of the 3 autocorrelation structures, we selected one fitted model based on AIC and performed model diagnostic results. As shown in Table 1, the selected model with the AR(2) error process has a slightly better AIC score (22.5) and adjusted $\mathrm{R}^{2}$ (81.5\%) than the model including lag-1 and lag-2 recruitment effects, with AIC $=24.0$ and adjusted $\mathrm{R}^{2}=80.7 \%$; the model-fitting results from both models are discussed in detail below. The AIC of the model containing lag- 2 and lag-3 recruitment (28.3) is much higher than the AICs from the other 2 selected models (Table 1), which indicates that this model is discredited by the data. Temperature was not significant in any of the models and was dropped from consideration. Including spring SST as an additive covariate results in an increase in the AIC for each of the 3 models reported in Table 1, 
Table 1. Akaike's information criterion (AIC) of the fitted models to predict walleye pollock recruitment in the Gulf of Alaska. The 3 models under comparison use different approaches for modeling the autocorrelations in the data. Here $\mathrm{s}(\mathrm{lag}-2)$ refers to a smooth function of the lag 2 of the recruitment; similarly defined is s(lag-3). According to AIC, Model (6) is chosen as the best model

\begin{tabular}{|lccc|}
\hline $\begin{array}{l}\text { Fitted } \\
\text { model }\end{array}$ & $\begin{array}{c}\text { Autocorrelation } \\
\text { mechanism }\end{array}$ & $\begin{array}{c}\text { Autocorrelation } \\
\text { structure }\end{array}$ & AIC \\
\hline Model (6) & $(3 \mathrm{a}-\mathrm{c})$ & $\mathrm{AR}(2)$ error process & 22.5 \\
Model (7) & $(4 \mathrm{a}-\mathrm{d})$ & lag-1 and s(lag-2) & 24 \\
$\begin{array}{l}\text { Variant } \\
\text { of Model (7) }\end{array}$ & & $\begin{array}{c}\text { lag-2 and monotone } \\
\text { s(lag-3) }\end{array}$ & 28.3 \\
\hline
\end{tabular}

Table 2. AIC of the models with various stochastic error process in structure (1). Based on AIC, the error process in Model (6) is specified as an order-2 autoregressive model

\begin{tabular}{|lc|}
\hline Autocorrelation structure & AIC \\
\hline No autoregressive & 35 \\
AR(1) error process & 34.8 \\
AR(2) error process & 22.5 \\
AR(3) error process & 23.9 \\
\hline
\end{tabular}

e.g. an increase in AIC from 22.5 to 24.2 for Model (6) with AR(2) error structure; similarly, other environmental factors, including fall SST and various wind speeds, were found to be inconsequential. We also fitted Model (6) with SST as the threshold variable, but that fitted model was deemed unacceptable based on model diagnostics and interpretation. Consequently, we shall confine our discussion to the first 2 models.

The first fitted model contains an autocorrelated error process $\left\{\xi_{t}\right\}$. Fitting results with different autoregressive structures in $\left\{\xi_{t}\right\}$ suggested that an AR(2) error process provided the best fit for the data with the lowest AIC values (Table 2). The mechanism for this AR(2) error process is shown by Eqs. (3a)-(3c). A preliminary analysis indicated that the log age-1 abundance $\left(y_{1, t}\right)$ and $\log$ arrowtooth flounder abundance $\left(a_{t}\right)$ after the threshold year $\left(t_{c}\right)$ were linearly correlated with the recruitment level $\left(y_{4, t+3}\right)$. Additionally, no environmental factors enter into the model, probably because any change in environmental factors that strongly influenced juvenile survival was incorporated in the threshold shift term. Therefore, the fitted model with the $\mathrm{AR}(2)$ error process has the following structure:

$$
y_{4, t+3}=\beta_{0}+\beta_{1} a_{t} 1_{\left(t>t_{c}\right)}+\beta_{2} y_{1, t}+\xi_{t+3}
$$

where the dummy variable $1_{\left(t>t_{C}\right)}$ equals 1 in the years after the threshold year $t_{c}$, and 0 otherwise, so $\beta_{1} a_{t} 1_{\left(t>t_{C}\right)}$ accounts for the threshold arrowtooth flounder preda- tion effect on pollock recruitment after year $t_{c}$. The errors form a stationary Gaussian AR(2) process: $\xi_{t}=\phi_{1} \xi_{t-1}+\phi_{2} \xi_{t-2}+\varepsilon_{t}$, where $\phi_{1}$ and $\phi_{2}$ are the autoregressive parameters and the $\varepsilon_{t}$ are independent and identically normally distributed errors, so that $\xi=\left(\xi_{t_{0}+3}, \xi_{t_{0}+4}, \ldots, \xi_{t_{L}+3}\right)^{T}$ follows a multivariate normal distribution $N\left(0, \sigma^{2} \Lambda\right)$, where $\left(t_{0}+3\right)$ and $\left(t_{L}+3\right)$ denote the first and last recruiting years of age-4 pollock in the study period, respectively, and $\Lambda$ is the correlation matrix with an AR(2) structure. More specifically, $\rho_{j}=$ $\phi_{1} \rho_{j-1}+\phi_{2} \rho_{j-2}, j \geq 2$, where $\rho_{j}$ is the correlation between $\xi_{t}$ and $\xi_{t-j}$, with the initial conditions $\rho_{0}=1, \rho_{1}=\phi_{1} /$ $\left(1-\phi_{2}\right)$ and $\sigma^{2}$ is the stationary variance of $\xi_{t}$.

To check whether the threshold structure of the arrowtooth flounder predation effect in Model (6) was appropriate for the data, we employed the likelihood ratio test discussed in the 'Methods'. The p-value of the likelihood ratio test for the threshold structure in Model (6) is 0.024. Thus, there is strong evidence that the flounder predation affected pollock recruitment after a threshold year $t_{c}$.

According to the profile AIC of the threshold years (Fig. 4), 1991 was estimated to be the threshold year for Model (6). Model (6) has 6 parameters, namely, $3 \beta$ values, 2 autoregressive coefficient parameters, and 1 threshold parameter. Thus, with a sample size of 22, the residuals have 16 degrees of freedom. As shown in Table 3 , the estimated $\beta_{1}$ equals $-0.052(\mathrm{SE}=9.17 \times$ $10^{-3}$ ), which indicates that arrowtooth flounder significantly decreases the recruitment of age- 4 walleye pollock, such that a $1 \%$ increase in flounder results, on average, in $0.052 \%$ decrease in recruitment. Additionally, the age-1 pollock abundance index is positively related with the recruitment of age-4 pollock $\left(\hat{\beta}_{2}=\right.$ 0.209 , SE $=0.039$ ), which indicates that age-1 abun-

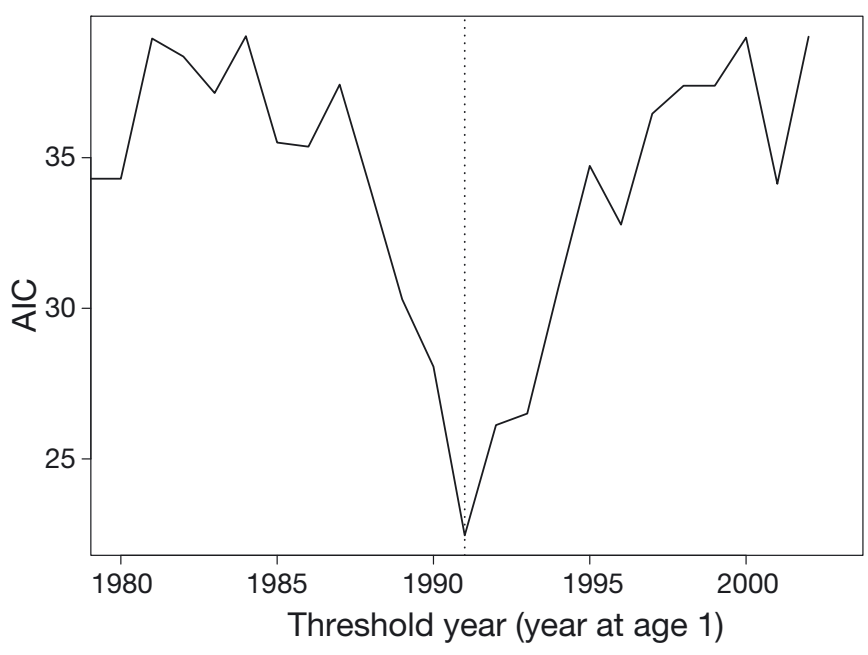

Fig. 4. Theragra chalcogramma. Akaike's information criterion (AIC) levels with different threshold years in Model (6) 
dance is an important factor explaining the variability in the recruitment of age- 4 pollock.

Based on the estimated autoregressive parameters, $\hat{\phi}_{1}=0.546$ and $\hat{\phi}_{2}=-0.719$ (Table 3 ), the error process $\left\{\xi_{t}\right\}$ is, indeed, stationary (see Cryer \& Chan 2008,

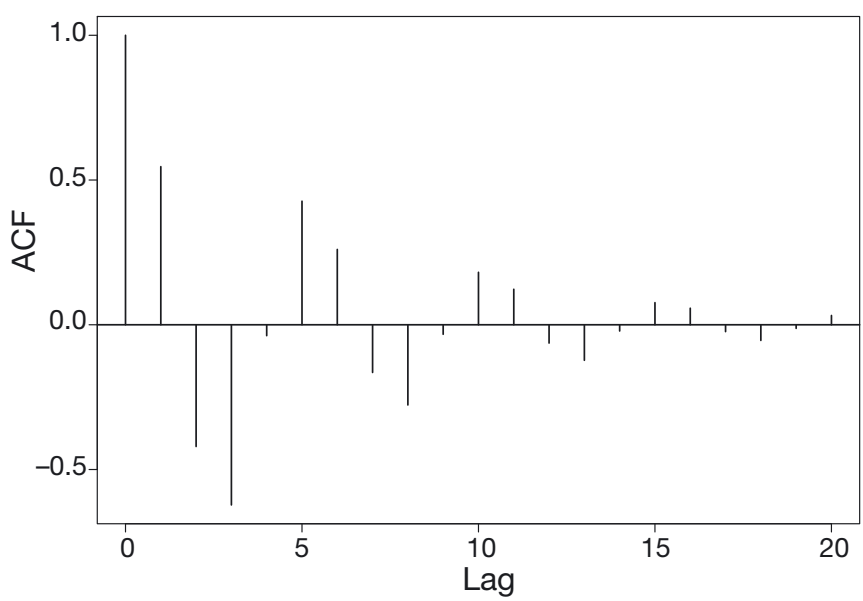

Fig. 5. Theragra chalcogramma. Theoretical autocorrelation function (ACF) of the $\mathrm{AR}(2)$ error process from the fitted Model (6), showing the quasiperiodicity of the error process p. 72). The average length of the stochastic cycle, $2 \pi / \cos ^{-1}\left[\phi_{1} /\left(2 \sqrt{-\phi_{2}}\right)\right]$, is approximately 5 yr (Fig. 5). The competition and cannibalism between the cohorts of different ages, especially the cannibalism of the adult pollock on the juveniles as detailed in Eqs. (3a)-(3c), are instrumental for the $5 \mathrm{yr}$ quasiperiodicity. Additionally, according to the discussion of the stochastic mechanism for this model in the previous section, the AR(1) parameter $\phi_{1}$ can be interpreted as the average survival rate of pollock of ages $4+$, which is estimated to be 0.546 (= 54.6\%), although with considerable uncertainty as the $95 \%$ confidence interval ranges from 28.5 to $63.5 \%$.

The normalized residuals equal the standardized residuals premultiplied by the inverse square root of the estimated error correlation matrix. In the model assumptions, the normalized errors follow the independent normal distribution with zero mean and constant variance. The linear trend in the $\mathrm{Q}-\mathrm{Q}$ normal plot of the normalized residuals (upper left plot in Fig. 6) and the Shapiro-Wilk normality test result ( $\mathrm{p}$-value = 0.58) suggest that the normal distribution assumption in the errors is satisfied. The scatter plot of the normalized residuals (upper right plot in Fig. 6) shows that the constant variance assumption for the normalized errors
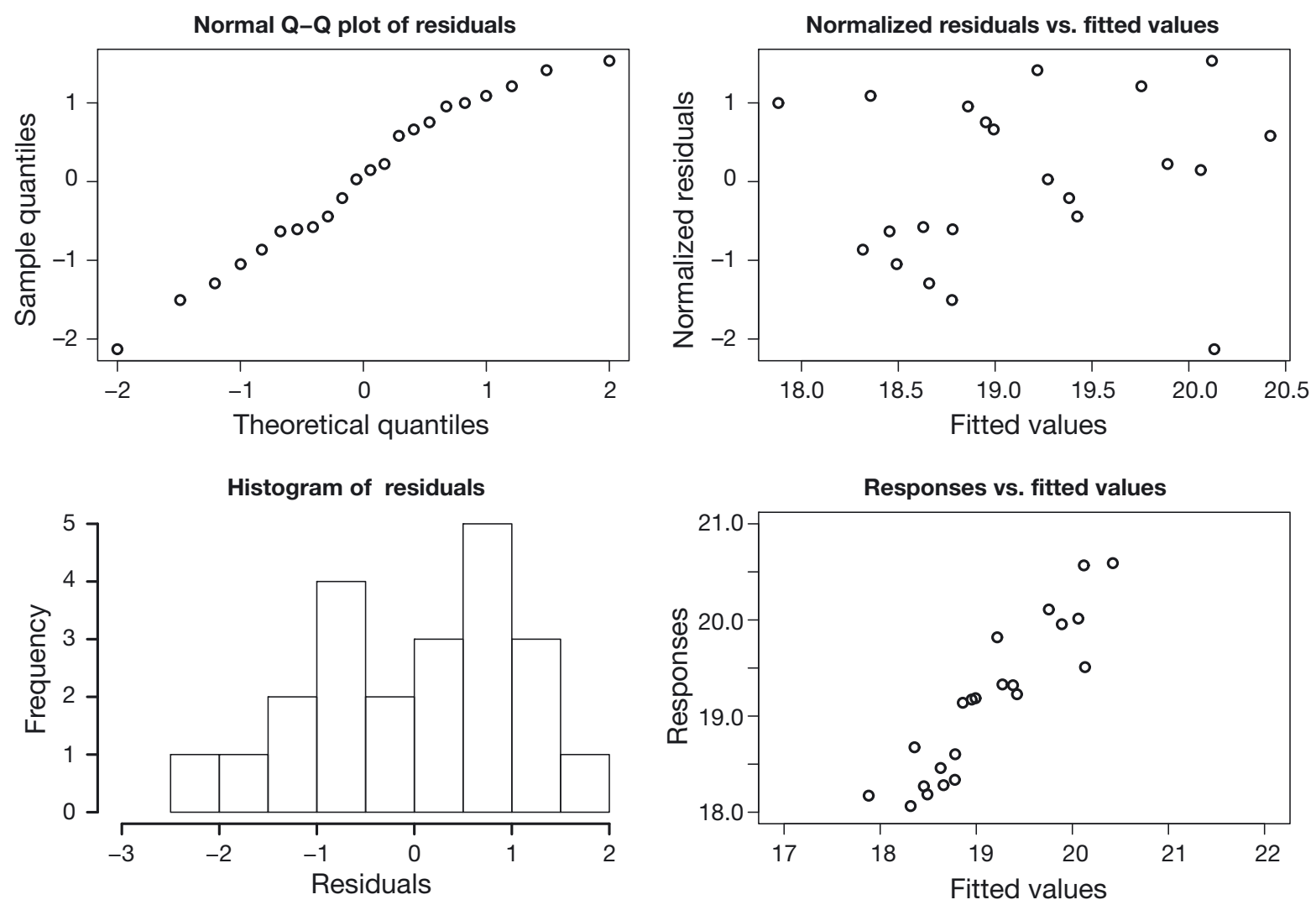

Fig. 6. Theragra chalcogramma. Residual check of Model (6) 
appears appropriate. The normalized residuals appear to be uncorrelated over time, which is supported by the ACF and Ljung-Box test. Therefore, the assumptions of the error terms are satisfied approximately for the fitted Model (6), suggesting that it provides a good fit to the data.

Owing to the AR(2) correlation structure in the error term, $\left\{\xi_{t}\right\}$ and that the covariates in Model (6) lag the recruitment by 3 yr, we can compute out-of-sample $k$ years ahead forecasts for $k=1,2$ and 3 yr into the future by the following formula:

$$
\hat{y}_{4, n+k}=\hat{\beta}_{0}+\hat{\beta}_{1} a_{n+k-3} 1_{\left(n+k-3>\hat{t}_{c}\right)}+\hat{\beta}_{2} y_{1, n+k-3}+\hat{\xi}_{n+k}
$$

where $\mathrm{n}$ is the last year of the study period, being 2006, and $\hat{\xi}_{n+k}$ are computed recursively by the formula:

$$
\hat{\xi}_{n+k}=\hat{\phi}_{1} \hat{\xi}_{n+k-1}+\hat{\phi}_{2} \hat{\xi}_{n+k-2}
$$

with $\hat{\xi}_{t}=y_{4, t}-\left(\hat{\beta}_{0}+\hat{\beta}_{1} a_{t-3} 1_{\left(t-3>\hat{t}_{c}\right)}+\hat{\beta}_{2} y_{1, t-3}\right)$ being the regression residuals from Model (6) for $t \leq \mathrm{n}$. For formulae to compute $95 \%$ prediction intervals see Chapter 9 in Cryer \& Chan (2008). For computing forecasts for 4 yr or longer, we needed to compute out-of-sample forecasts for arrowtooth flounder abundance and that of $1 \mathrm{yr}$ old walleye pollock, which required the development of joint modeling for these covariate processes with the recruitment. Note that $y_{1, t}$ in year 1999 was a missing value, and we used the naïve scheme of averaging the $y_{1, t}$ values in 1998 and 2000 to imput this missing log age-1 abundance index. The fitted recruitment of age-4 pollock in 2002 was calculated based on the imputed age-1 abundance in 1999.

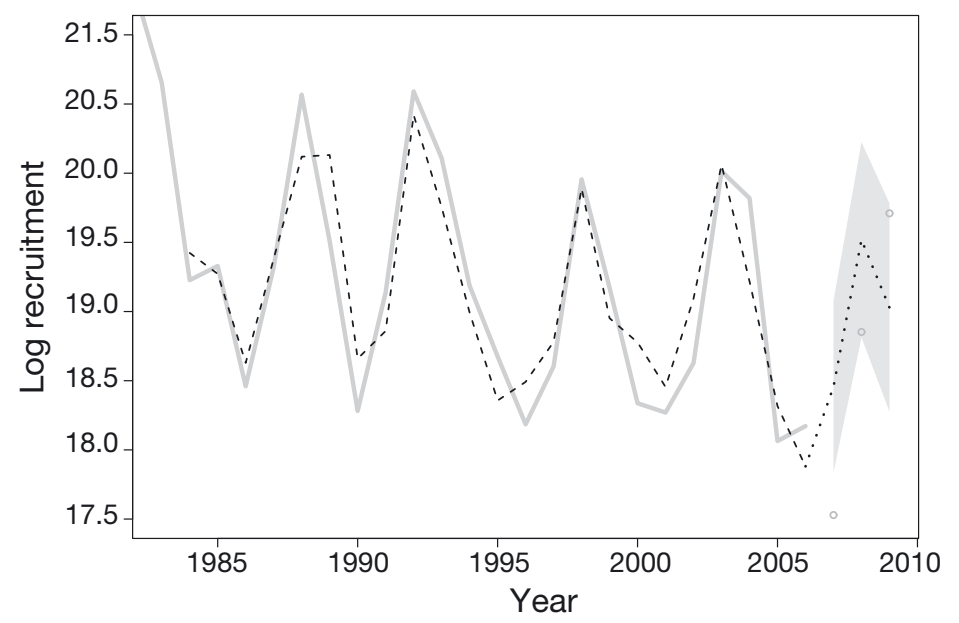

Fig. 7. Theragra chalcogramma. Observed recruitment and predicted recruitment from Model (6). Numbers are abundance of $4 \mathrm{yr}$ old fish occurring in each year. Gray solid line: observed recruitment over the study period; dashed line: estimated recruitment; dotted line: out-of-sample recruitment forecasts; gray shaded area: $95 \%$ point-wise prediction band of the recruitment forecasts; $\circ$ : recent observed recruitment in 2007 to 2009
Recruitment estimates and out-of-sample (point) forecasts, i.e. conditional means of the future values, from Model (6) for $3 \mathrm{yr}$ are shown in Fig. 7. The dynamic trend shown by the fitted walleye pollock recruitment levels (dashed curve) follows the observed recruitment trend (gray curve) in the study period, which indicates that the recruitment Model (6) fits the data well. The (log) recruitment forecasts of the age-4 fish for 2007, 2008 and 2009 are 18.5, 19.5 and 19.0, respectively, resulting in the forecast errors (forecasts minus observations) being $0.93,0.67$ and -0.68 , respectively. The dotted curve in Fig. 7 plots the recruitment forecasts of the age-4 pollock from 2007 to 2009, with the $95 \%$ point-wise prediction band shaded in gray; the point forecast for 2007 is just outside the $95 \%$ prediction interval (but still successfully predicts a weak year class), while the point forecasts for 2008 and 2009 are both inside their $95 \%$ prediction intervals.

The second fitted recruitment model uses lag-1 and lag-2 recruitment to account for the (extra) autocorrelation among the age-4 recruitment. The autocorrelation structure can be explained by the population dynamics described by Eqs. (4a)-(4d), with the greater flexibility in a nonlinear lag-2 effect. The threshold arrowtooth flounder predation effect and age-1 abundance effect are still found to be linear. The formulation of this fitted model is as follows:

$$
y_{4, t+3}=\beta_{0}+\beta_{1} a_{t} 1_{\left(t>t_{c}\right)}+\beta_{2} y_{1, t}+\beta_{3} y_{4, t+2}+s\left(y_{4, t+1}\right)+\varepsilon_{t+3}
$$

where $\beta_{3} y_{4, t+2}$ represents a linear lag-1 recruitment effect, and $s\left(y_{4, t+1}\right)$ assesses the lag-2 recruitment effects nonparametrically. The term $\left\{\varepsilon_{t+3}\right\}$ is a sequence of uncorrelated error terms that are of zero mean and constant variance.

Model (7) considers that the strong arrowtooth flounder predation effects take place only after a threshold year. Before accepting the fit of Model (7), we determine whether the threshold effect is significant in the recruitment model. Using the likelihood ratio test, we find strong evidence for the threshold structure embodied in Model (7) with p-value being equal to 0.002. Additionally, according to the AIC values under

Table 3. Estimates of Model (6) for predicting walleye pollock recruitment using 1991 as the threshold year. The estimates are obtained by maximum likelihood estimation, via the arimax function in $\mathrm{R}$

\begin{tabular}{|cccrr|}
\hline & Value & SE & $t$-value & p-value \\
\hline$\beta_{0}$ & 20.0 & $1.33 \times 10^{-1}$ & 149.78 & $<0.001$ \\
$\beta_{1}$ & -0.0520 & $9.17 \times 10^{-3}$ & -5.67 & $<0.001$ \\
$\beta_{2}$ & 0.209 & $3.86 \times 10^{-2}$ & 5.41 & $<0.001$ \\
$\phi_{1}$ & 0.546 & $1.43 \times 10^{-1}$ & 3.82 & 0.002 \\
$\phi_{2}$ & -0.71 & $1.31 \times 10^{-2}$ & -5.50 & $<0.001$ \\
\hline
\end{tabular}


Table 4. Estimates of Model (7) for predicting walleye pollock recruitment using 1991 as the threshold year. The model was fitted using the gam function of the mgcv library in R

\begin{tabular}{|cccrr|}
\hline & Value & SE & $t$-value & p-value \\
\hline$\beta_{0}$ & 15.1 & 2.02 & 7.49 & $<0.001$ \\
$\beta_{1}$ & -0.0594 & $1.14 \times 10^{-2}$ & -5.21 & $<0.001$ \\
$\beta_{2}$ & 0.179 & $4.89 \times 10^{-2}$ & 3.66 & 0.002 \\
$\beta_{3}$ & 0.252 & $1.04 \times 10^{-1}$ & 2.43 & 0.028 \\
\hline
\end{tabular}

different threshold choices, the estimated threshold year is 1991 .

The estimation results of Model (7) are given in Table 4. The slope of the linear arrowtooth flounder predation effect after 1991 is $-0.059\left(\mathrm{SE}=1.14 \times 10^{-2}\right)$, which indicates that a high density of flounder tends to reduce the recruitment of age-4 pollock. Meanwhile, the positive slope $\left(\hat{\beta}_{2}=0.179, \mathrm{SE}=4.89 \times 10^{-2}\right)$ of the linear age- 1 abundance effect indicates that the higher age-1 abundance is associated with the higher recruitment level. The positive estimate $\hat{\beta}_{2}=0.252$ ( $\mathrm{SE}=$ $0.104)$ suggests that the misclassification effect overwhelms the competition and/or cannibalism from the lag-1 recruitment. The decreasing pattern in its 'lag 2 effects' (Fig. 8) shows that the age-4 recruitment is negatively correlated with its lag-2 recruitment, which is consistent with the mechanism underlying Eq. (4a)-(4d). The smooth function estimate $s\left(y_{4, t+1}\right)$ has 1.64 degrees of freedom, so Model (7) has about 6.64 parameters, slightly more than that of Model (6), and its residuals have 15.36 degrees of freedom.

Through the model diagnostics, we find that the residuals of Model (7) marginally satisfied the ShapiroWilks normality test with p-value being equal to 0.07 , which was slightly higher than the 0.05 significance

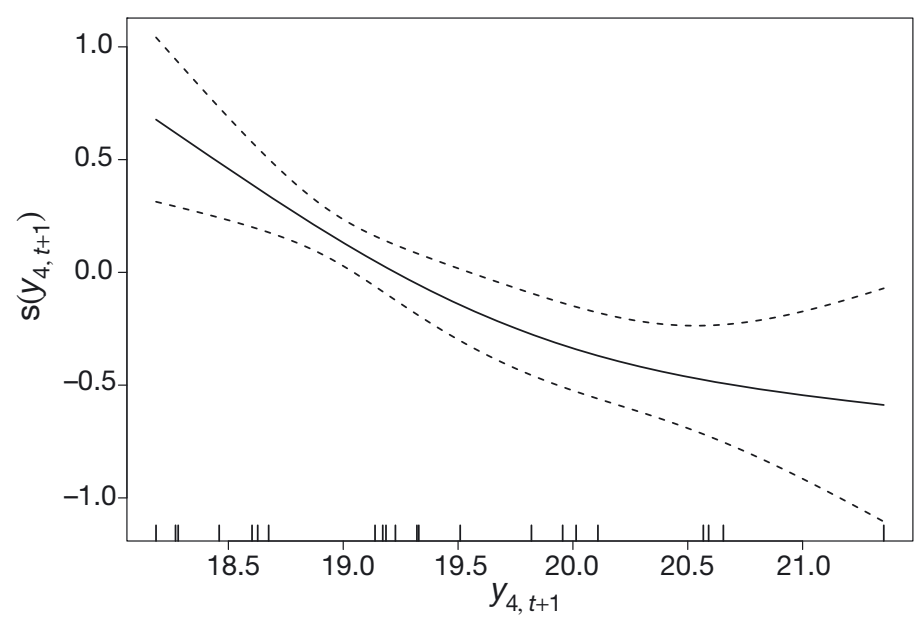

Fig. 8. Theragra chalcogramma. Additive lag-2 recruitment effects of Model (7)

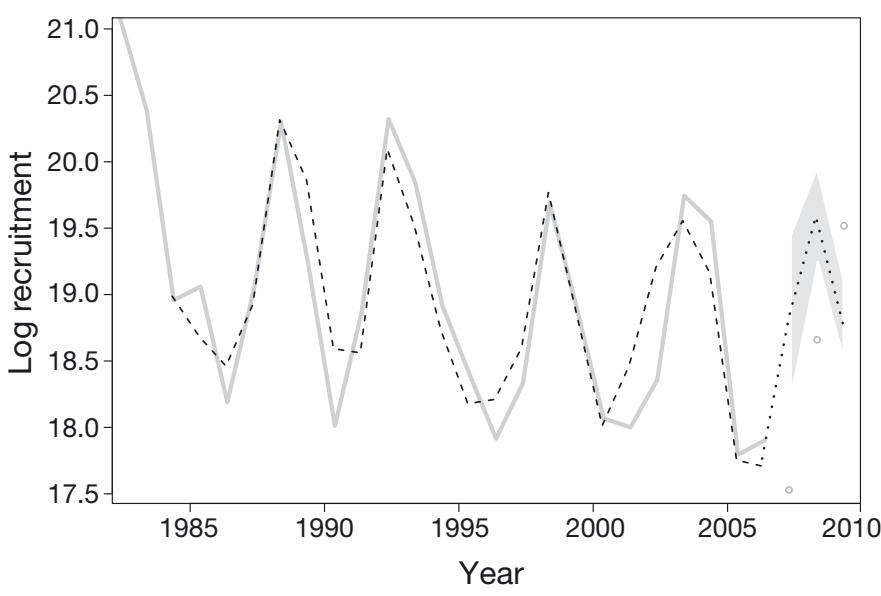

Fig. 9. Theragra chalcogramma. Observed recruitment and predicted recruitment from Model (7). Gray solid line: observed recruitment over the study period; dashed line: estimated recruitment; dotted line: out-of-sample recruitment forecasts; gray shaded area: $95 \%$ point-wise prediction band of the recruitment forecasts; $\circ$ : recent observed recruitment (of age-4 pollock) in 2007 to 2009

level. All the other assumptions of the error terms, such as the constant variance and independence, are approximately satisfied. Overall, the residual diagnostics of Model (7) are not as good as those of Model (6), although they look similar to Fig. 6, so they are not shown here. Additionally, the out-of-sample forecasts from Model (7) (dotted curve in Fig. 9) are less accurate than those from Model (6) as all of the forecasts fall outside the $95 \%$ prediction intervals (although the general predictions of weak or moderate year classes are accurate). The forecast errors (forecasts minus observations) in 2007, 2008 and 2009 equal 1.52, 0.95 and -0.71, respectively, which are larger in magnitude than their counterparts from Model (6). However, the within-sample recruitment estimation from Model (7) fits the observed recruitment data well (dashed curve in Fig. 9).

\section{DISCUSSION}

The dynamics of marine fish populations respond to many factors. One of the world's largest fisheries, walleye pollock, has experienced sequential and lasting declines of populations in Puget Sound, Shelikof Strait, the Aleutian Basin and other regions in the northern Pacific Ocean, most probably due to the combined effects of climate change (Ciannelli et al. 2005), shifts in community structure (Anderson \& Piatt 1999, Litzow \& Ciannelli 2007) and possibly harvesting activity. The Gulf of Alaska population decreased to about $22 \%$ of its prefishing biomass in 2003 and is currently at 30\% (Dorn et al. 2009). Under such circumstances, forecast- 
ing recruitment to the population is important as the commercial harvest takes increasingly younger members of the population. The traditional methods of forecasting marine fisheries recruitment from environmental conditions during egg and larval stages have been marginally successful due to the complexity of interacting biological and environmental conditions coupled with the high and variable mortality of these early life history stages (Bailey et al. 2005, Houde 2008), although there are exceptions (Svendsen et al. 2007). Here we demonstrate some novel forecasting models that are fairly successful. In our forecasting models we start with 1 yr old juvenile walleye pollock abundance in survey catches and examine factors that may influence their survival over the next 3 to $4 \mathrm{yr}$ until recruitment. We find that a change in the predator community favoring an increase in the abundance of arrowtooth flounder (a voracious predator of juvenile pollock that has come to dominate the groundfish biomass in the Gulf of Alaska in the past decade, Turnock \& Wilderbuer 2007), a strong autocorrelation effect probably caused by year class interactions and a threshold effect in predation that is linked with a phase shift in environmental factors are closely coupled with recruitment predictability. These findings represent a new approach in forecasting recruitment success of marine fisheries and further demonstrate the importance of predation during the juvenile stage influencing the dynamics of marine fish populations.

Recruitment of walleye pollock became decoupled from larval mortality in the early 1990s and control shifted to juvenile survival (Bailey 2000); a shift in community structure also occurred around the same time that included a marked increase in the abundance of flatfishes (Anderson \& Piatt 1999), particularly arrowtooth flounder. In general, larval dynamics are thought to activate variability in year class strength, whereas predation on juveniles is thought to dampen variability (van der Veer 1986, Bailey et al. 2005). However, arrowtooth flounder has become an important force in the recruitment of pollock, as this flounder is currently the dominant groundfish species and predator in the Gulf of Alaska ecosystem. Arrowtooth flounder biomass dwarfs that of other potential predators, such as Pacific cod Gadus macrocephalus, by about an order of magnitude (NPFMC 2009). Generally about 40 to $50 \%$ of the diet of adult arrowtooth flounder comprises juvenile walleye pollock although the exact composition and lengths of fish preyed upon depends on availability (Yang 1993, Yang et al. 2006, Knoth \& Foy 2008). Shifts in community structure resulting in changes in abundance of top predators are recognized to have major cascading effects on lower trophic levels (Hunt et al. 2002, Frank et al. 2005). We perceive that if and/or when arrowtooth flounder abundance in the
GOA declines, other predators may become important factors in juvenile pollock survival, leading to a forecasting strategy that includes adaptable models.

A threshold effect on the importance of arrowtooth flounder predation on walleye pollock seems to have occurred around the same time that control of pollock recruitment shifted to juvenile survival. In this sense inclusion of the threshold in the model is consonant with the known biology. We suggest the possibility that an increasing arrowtooth flounder population may have been conditioned over time to locate predictable 'hotspots' on age-1 juvenile pollock resulting in a phase transition, or their distribution otherwise expanded at that time to overlap more with juvenile pollock. Recent studies have shown that whereas age-0 pollock distributions are variable from year to year, age-1 (Wilson 2009) and older fish distributions (Shima et al. 2002) are relatively consistent. Alternatively an environmental phase shift occurring around the same time (i.e. 1989, Hollowed et al. 2001), potentially causing a shift in the overlapping distributions of predator and prey, could be a factor (Ciannelli et al. 2005). An environmental shift that started around 1989 was associated with changes in a broad array of biological and climate factors, including enhanced summer warming in the coastal waters of the GOA (Hare \& Mantua 2000). Yet another alternative is that the acoustic gear changed in 1992, near our threshold year, and this gear change may have altered the log-transformed data by some additive constant after 1992, resulting in a jump in the intercept term; however, this effect cannot produce the piece-wise linear threshold effects described in Models (6) and (7).

Our initial modeling efforts included an interaction effect of temperature and arrowtooth flounder abundance on walleye pollock recruitment. Although the final model dropped the temperature interaction, it is likely to be an important consideration in the overlap of predators and prey; in our case its precision may have been affected by using SST as a proxy for bottom temperature (BT). In the Bering Sea arrowtooth flounder avoid cold water (Spencer 2008). In the GOA, there is some support that arrowtooth flounder tend to avoid cold water; for example in colder La Niña years they are found in warmer areas (Speckman et al. 2005). We suggest that in some years arrowtooth flounder may avoid cold water over the shelf, influencing their overlap with juvenile pollock prey. More studies, better understanding of temperature interactions and availability of bottom temperature data may indicate whether temperature effects should be included in future models.

The autocorrelation among the walleye pollock recruits included in our models reflects the pollock's population dynamics, which is difficult to explain but is biologically plausible. The sometimes cyclic nature of 
population dynamics is well established (e.g. Kendall et al. 1999, Stenseth et al. 2003). Cyclic variations in recruitment of marine fishes can occur on many scales, from lunar (Meekan et al. 1993) to decadal and longer cycles (Southward et al. 1988, Ravier \& Fromentin 2001). Marine fish recruitment cycles with a period approximating a generation time (4 to 5 yr for walleye pollock) may result from intrapopulation interactions (Bjornstad et al. 1999, Bailey et al. 2003). In the fitted models with stochastic error terms, the dynamic cycle may be due to the competition or cannibalism effects from older pollock groups (Bjornstad et al. 1999). Walleye pollock in the Bering Sea are highly cannibalistic and there is a strong seasonality in the process (Dwyer et al. 1987) with up to 50 to $90 \%$ of the diet of adults in autumn and winter comprised of juveniles, mainly age-0 fish. There is also a high degree of cannibalism on age-1 pollock in the eastern Hokkaido Island stock of pollock (Yamamura et al. 2001). In the GOA there is little published information on seasonal changes in the diet of pollock, but in summer around $10 \%$ of the diet of adults consisted of juvenile pollock (Yang 1993, Yang et al. 2006). Competition between year classes and between adults and juveniles is also viable since a large component of the diet of both age-1 pollock and adults is comprised of copepods and euphausids. Competition between year classes is also thought to be important in recruitment of pollock off eastern Hokkaido Island (Shida et al. 2007). Autocorrelation in juvenile survival rates may also be linked to autocorrelation in environmental variables, such as zooplankton biomass in the GOA and/or competitor effects on prey (Brodeur et al. 1996, Shiomoto et al. 1997). Consequently, we believe that the autocorrelation in pollock dynamics is important to capture in forecasting models, and a better understanding of this phenomenon is needed.

The models we propose for walleye pollock recruitment forecasting are novel in the sense that they are based on indices that come after the complex egg and larval period, starting with survey estimates of age-1 juveniles. The models account for changes in community structure, such as an increasing trend in the predatory capacity of the community, and for biological causes of the observed periodicity in recruitment. In the hindcast mode, Model (6) in particular provides a very close fit to observed recruitment levels, and the forecasts for $4 \mathrm{yr}$ old fish recruiting in 2007-2009 appear to be relatively accurate. This model, which has a slightly better fit than Model (7) based on AIC and adjusted $\mathrm{R}^{2}$ as well as model diagnostics, accounts for the effects of age-1 abundance, the threshold effect of arrowtooth flounder abundance and autocorrelated error terms due to as yet unidentified covariates on recruitment 3 yr later. Furthermore, Model (6) provides a far superior fit (adjusted $\mathrm{R}^{2}=81.5 \%$ ) than the simple linear regression with the log age-1 abundance as the only covariate (adjusted $\mathrm{R}^{2}=31.2 \%$ ). Model (7) is more specific and provided insight to the possible missing covariates, including potential misclassifying ages of adult pollock (especially spillover effects of strong year classes) and predation/competition interactions among cohorts. There may be other covariates involving stock structure and spawning behavior, or competition and cannibalism (and their representation), underlying the $A R(2)$ error structure that are not presently recognized.

\section{LITERATURE CITED}

Anderson P, Piatt JF (1999) Community reorganization in the Gulf of Alaska following ocean climate regime shift. Mar Ecol Prog Ser 189:117-123

> Axenrot T, Hansson S (2003) Predicting herring recruitment from young-of-the-year densities, spawning stock biomass, and climate. Limnol Oceanogr 48:1716-1720

Bailey KM (2000) Shifting control of recruitment of walleye pollock (Theragra chalcogramma) after a major climate and ecosystem change. Mar Ecol Prog Ser 198:215-224

Bailey KM, Ciannelli L, Agostini V (2003) Complexity and constraints combined in simple models of recruitment. In: Browman HI, Skiftesvik AB (eds) The big fish bang. Proc 26th Annu Larval Fish Conf. Institute of Marine Research, Bergen, Norway, p 293-301. Also available at: www.fishlarvae.com/e/BigBang/Bailey.pdf

Bailey KM, Ciannelli L, Bond N, Belgrano A, Stenseth NC (2005) Recruitment of walleye pollock in a complex physical and biological ecosystem. Prog Oceanogr 67:24-42

Bjørnstad ON, Fromentin JM, Stenseth NC, Gjøsætter J (1999) Cycles and trends in cod populations. Proc Natl Acad Sci USA 96:5066-5071

Bradford MJ (1992) Precision of recruitment predictions from early life stages of marine fishes. Fish Bull 90:439-453

Brodeur RD, Frost BW, Hare SR, Francis RC, Ingraham WJ (1996) Interannual variations in zooplankton biomass in the Gulf of Alaska, and covariation with California Current zooplankton biomass. CCOFI Rep 37:80-98

Ciannelli L, Bailey KM, Stenseth NC, Chan KS, Belgrano A (2005) Climate change causing phase transition of walleye pollock (Theragra chalcogramma) recruitment dynamics. Proc Biol Sci 272:1735-1743

Cryer DJ, Chan KS (2008) Time series analysis with applications in R. Springer Verlag, New York

Dorn M, Aydin K, Barbeaux S, Guttormsen M, Megrey B, Spalinger K, Wilkins M (2006) Stock assessment and fishery evaluation report: assessment of walleye pollock in the Gulf of Alaska. North Pacific Fishery Management Council,Anchorage, AK. Also available at: www.afsc.noaa.gov/ refm/docs/2006/GOApollock.pdf

Dorn M, Aydin K, Barbeaux S, Guttormsen M, Megrey B, Spalinger K, Wilkins M (2009) Stock assessment and fishery evaluation report: Gulf of Alaska walleye pollock. North Pacific Fishery Management Council, Anchorage, AK. Also available at: www.afsc.noaa.gov/REFM/docs/ 2009/GOApollock.pdf

$>$ Dwyer DA, Bailey KM, Livingston PA (1987) Feeding habits and daily ration of walleye pollock (Theragra chalcogramma) in the eastern Bering Sea, with special reference to cannibalism. Can J Fish Aquat Sci 44:1972-1984 
Frank KT, Petrie B, Choi JS, Leggett WC (2005) Trophic cascades in a formerly cod-dominated ecosystem. Science 308:1621-1623

Hare SR, Mantua NJ (2000) Empirical evidence for North Pacific regime shifts in 1977 and 1989. Prog Oceanogr 47: 103-145

> Helle K, Bogstad B, Marshall TT, Michalsen K, Ottersen G, Pennington $M$ (2000) An evaluation of recruitment indices for Arcto-Norwegian cod (Gadus morhua L.). Fish Res 48: $55-67$

Hjort J (1914) Fluctuations in the great fisheries of northern Europe, viewed in the light of biological research. Rapp P-V Reun Conseil Int Explor Mer 20:1-228

Hollowed AB, Hare SR, Wooster WS (2001) Pacific basin climate variability and patterns of Northeast Pacific marine fish production. Prog Oceanogr 49:257-282

Houde ED (2008) Emerging from Hjort's shadow. J Northwest Atl Fish Sci 41:53-70

Hunt GL Jr, Stabeno P, Walters G, Sinclair E, Brodeur RD, Napp JM, Bond NA (2002) Climate change and control of the southeastern Bering Sea pelagic ecosystem. Deep-Sea Res II 49:5821-5854

Kendall BE, Briggs CJ, Murdoch WW, Turchin P and others (1999) Why do populations cycle? A synthesis of statistical and mechanistic modeling approaches. Ecology 80: 1789-1805

Knoth BA, Foy RJ (2008) Temporal variability in the food habits of arrowtooth flounder (Atheresthes stomias) in the western Gulf of Alaska. NOAA Tech Memo NMFS-AFSC184

Lee YW, Megrey BA, Mackin SA (2009) Evaluating the performance of Gulf of Alaska walleye pollock (Theragra chalcogramma) recruitment forecasting models using a Monte Carlo resampling strategy. Can J Fish Aquat Sci 66: $367-381$

Lin X, Zhang D (1999) Inference in generalized additive mixed models using smoothing splines. J R Stat Soc B 61: $381-400$

Litzow MA, Ciannelli L (2007) Oscillating trophic control induces community reorganization in a marine ecosystem. Ecol Lett 10:1124-1134

McKelvey DR (1996) Juvenile pollock distribution and abundance in Shelikof Strait. What can we learn from acoustic survey results? NOAA Tech Rep 126:25-34

Meekan MG, Milicich MJ, Doherty PJ (1993) Larval production drives temporal patterns of larval supply and recruitment of a coral reef damselfish. Mar Ecol Prog Ser 93: $217-225$

Mukhina NV, Marshall CT, Yaragina NA (2003) Tracking the signal in year-class strength of northeast Arctic cod through multiple survey estimates of egg, larval and juvenile abundance. J Sea Res 50:57-75

NOAA (2008) NOAA 200th visions: ocean research. Available at: celebrating200years.noaa.gov/visions/ocean_research/ welcome.html

NPFMC (North Pacific Fishery Management Council) (2009) Stock assessment and fishery evaluation report for the groundfish resources of the Gulf of Alaska. North Pacific Fishery Management Council, Anchorage, AK. Also available at: www.afsc.noaa.gov/REFM/Docs/2009/GOASafe. pdf

Editorial responsibility: Alejandro Gallego, Aberdeen, UK
Ravier C, Fromentin JM (2001) Long-term fluctuations in the eastern Atlantic and Mediterranean bluefin tuna population. ICES J Mar Sci 58:1299-1317

Shida O, Hamatsu T, Nishimura A, Suzaki A, Yamamoto J, Miyashita K, Sakurai Y (2007) Interannual fluctuations in recruitment of walleye pollock in the Oyashio region related to environmental changes. Deep-Sea Res II 54: $2822-2831$

Shima M, Hollowed AB, VanBlaricom GR (2002) Changes over time in the sptial distribution of walleye pollock (Theragra chalcogramma) in the Gulf of Alaska, 1984-1996. Fish Bull 100:307-323

> Shiomoto A, Tadokoro K, Nagasawa K, Ishida Y (1997) Trophic relations in the subarctic North Pacific ecosystem: possible feeding effect from pink salmon. Mar Ecol Prog Ser 150:75-85

Southward AJ, Boalch GT, Maddock L (1988) Fluctuations in the herring and pilchard fisheries of Devon and Cornwall linked to change in climate since the 16th century. J Mar Biol Assoc UK 68:423-445

Speckman SG, Piatt JF, Minte-Vera CV, Parrish JK (2005) Parallel structure among environmental gradients and three trophic levels in a subarctic estuary. Prog Oceanogr 66:25-65

Spencer PD (2008) Density-independent and density-dependent factors affecting temporal changes in spatial distributions of eastern Bering Sea flatfish. Fish Oceanogr 17:396-410

Stenseth NC, Viljugrein $\mathrm{H}$, Saitoh $\mathrm{T}$, Hansen TF, Kittilsen MO, Bolviken E, Glockner F (2003) Seasonality, density dependence, and population cycles in Hokkaido voles. Proc Natl Acad Sci USA 100:11478-11483

Svendsen E, Skogen M, Budgell P, Huse G and others (2007) An ecosystem modeling approach to predicting cod recruitment. Deep-Sea Res II 54:2810-2821

Turnock BJ, Wilderbuer TK (2007) Stock assessment and fishery evaluation report: Gulf of Alaska arrowtooth flounder stock assessment. North Pacific Fishery Management Council, Anchorage, AK. Also available at: www.afsc. noaa.gov/refm/docs/2007/GOAatf.pdf

> van der Veer HW (1986) Immigration, settlement, and density-dependent mortality of a larval and early postlarval 0group plaice (Pleuronectes platessa) population in the western Wadden Sea. Mar Ecol Prog Ser 29:223-236

Walters CJ, Collie JS (1988) Is research on environmental factors useful to fisheries management? Can J Fish Aquat Sci 45:1848-1854

Wilson MT (2009) Ecology of small neritic fishes in the western Gulf of Alaska. I. Geographic distribution in relation to prey density and the physical environment. Mar Ecol Prog Ser 392:223-237

Wood SN (2006). Generalized additive models: an introduction with R. Chapman \& Hall/CRC Press, Boca Raton, FL

> Yamamura O, Yabuki K, Shida O, Watanabe K, Honda S (2001) Spring cannibalism on 1 year walleye pollock in the Doto area, northern Japan: Is it density dependent? J Fish Biol 59:645-656

Yang M (1993) Food habits of the commercially important groundfishes in the Gulf of Alaska in 1990. NOAA Tech Memo NMFS-AFSC-22:1-150

Yang MS, Dodd K, Hibpshman R, Whitehouse A (2006) Food habits of groundfishes in the Gulf of Alaska in 1999 and 2001. NOAA Tech Memo NMFS-AFSC-164:1-199

Submitted: April 30, 2010; Accepted: September 8, 2010

Proofs received from author(s): October 18, 2010 